\title{
Mean Platelet Volume as a Marker of Intraventricular Hemorrhage in Very Premature Infants
}

\author{
Ziba Mosayebi, ${ }^{1,2}$ Mahdi Sepidarkish, ${ }^{3}$ Zahra Nikseresht, ${ }^{4}$ Marzieh Sharifi, ${ }^{4}$ Setareh Sagheb, ${ }^{1, *}$ and \\ Shahin Nariman ${ }^{4}$ \\ ${ }^{1}$ Department of Pediatrics, Tehran University of Medical Sciences, Tehran, IR Iran \\ ${ }^{2}$ Children's Medical Center, Pediatrics Center of Excellence, Tehran, IR Iran \\ ${ }^{3}$ Department of Epidemiology and Reproductive Health, Reproductive Epidemiology Research Center, Royan Institute for Reproductive Biomedicine, Tehran, IR Iran \\ ${ }^{4}$ Faculty of Medicine, Tehran University of Medical Sciences, Tehran, IR Iran \\ "Corresponding author: Setareh Sagheb, Division of Neonatology, Shariati Hospital, Tehran University of Medical Sciences, Tehran, IR Iran. Tel: +98-9122387976, E-mail: \\ dr.ssagheb@yahoo.com
}

Received 2016 August 15; Revised 2017 January 17; Accepted 2017 March 19.

\begin{abstract}
Background: Since the intraventricular hemorrhage (IVH) is still a serious problem in premature infants associated with poor neurodevelopmental outcomes, there is a need for an accessible tool in order to identify these at high risk neonates.

Objectives: To determine if high mean platelet volume (MPV) within 24 hours of birth can identify preterm infants prone to IVH as a simple accessible test.

Methods: One hundred premature infants with gestational age (GA) of $<34$ weeks with respiratory distress syndrome (RDS) were eligible in this study and were divided into two groups based on the diagnosis of IVH. Measurements of MPV and platelet counts were performed during the first hours of admission and on the third day of life. Elevated MPV was defined as a value of $\geq 11 \mathrm{fL}$.

Results: Seventy four percent of infants with IVH had an MPV of more than $11 \mathrm{fL}$ compared to twenty six percent in infants without IVH (Crude OR: 10.71, 95\%CI: 4.26 to 26.90, P < 0.001). Multivariate logistic regression analysis of selected variables demonstrated that MPV (Adjusted OR: 10.68, 95\%CI: 3.20 to 35.59, P < 0.001) and GA (Adjusted OR: 0.54, 95\%CI: 0.40 to $0.74, \mathrm{P}<0.001$ ) were related to the occurrence of IVH.

Conclusions: High MPV within 24 hours of birth can be determined as a simple available laboratory test for identifying NICUadmitted premature infants at risk of IVH.
\end{abstract}

Keywords: Mean Platelet Volume (MPV), Preterm Infants, Intra Ventricular Hemorrhage (IVH)

\section{Background}

Even though the incidence of intraventricular hemorrhage (IVH) has declined by increasing the use of antenatal corticosteroids and the postnatal use of surfactant (1-3), it is still a serious problem in premature infants associated with poor neurodevelopmental outcomes (4-6). Imperfect autoregulation of cerebral blood flow (CBF) (7) and increased serum level of interleukins (ILs: interlukin-1 beta, interlukin-6, interlukin-8, interlukin-18) and tumor necrosis factor-alpha were observed to be linked with severe IVH in extremely premature infants and are associated with neurodevelopmental disorders in this group (8-11) Mean platelet volume (MPV) as an accessible predictive marker in thromboembolic events such as strokes and acute myocardial infarction in adults has already been studied (1214). Destruction of platelets in the periphery increases the production of platelets by bone marrow that leads to an increase in the number of immature platelets in the circulatory system, thus leading to high MPV (14-16).
Clinical evidence suggests that platelets play a crucial role in inflammatory response. Proinflammatory cytokines stimulate megakaryocytes to increase the number of platelets in response to inflammation (17). Due to these physiologic changes, any condition that is associated with activation of proinflammatory cytokines and interleukins should increase MPV. Previous studies suggested the possible correlation between MPV and respiratory distress syndrome (RDS) (18), broncopulmonary dysplasia (BPD) (19) and IVH (20) in preterm infants.

This study aims to assess the feasibility of MPV within 24 hours of birth as a simple accessible tool to identify preterm infants prone to IVH in a large case group with lower gestational age and also to evaluate MPV in relation to IVH grades. 


\section{Methods}

\subsection{Study Design}

This case control study was conducted during 18 months from January 2014 to June 2015 on all preterm infants (gestational age $<34$ weeks) with diagnosis of RDS who were admitted to the NICU of Arash hospital in Tehran, soon after birth. Preterm infants with IVH constituted the case group and those without IVH were included as control group. The study was approved by the local Ethical Committee and written consent was obtained from parents before enrollment. Inclusion criteria: any premature infant with gestational age (GA) of $<34$ weeks with diagnosis of RDS in accordance with the European consensus guidelines (21). Exclusion criteria: 1. infants born to a mother with preeclampsia or any drug history which could have negative effects on platelet counts 2 . Major congenital abnormalities at birth 3. Congenital thrombocytopenia (platelet $<150,000 \times 10^{9} / \mathrm{L}$ ). 4 . Gastro-intestinal tract problems needing surgical intervention.

Demographic data including sex, gestational age, maternal age, birth weight, mother's underlying disease, parity, metabolic acidosis, pneumothorax, patent ductus arteriosus (PDA), platelets and MPV level were recorded.

\subsection{Diagnosis of IVH}

On the third day of life, the routine cranial ultrasonography (CUS) was performed. For very sick infants or birth weight $\leq 1000$ gr, CUS was carried out within 24 hours of birth. Serial CUS was performed according to grading of IVH (22).

\subsection{Blood Samples}

To avoid any measurement bias, blood samples for the complete blood cell count (CBC) and blood gas were collected at the time of NICU admission. The CBC test was repeated on the third day. Blood gas analyses were performed in the Radiometer device ABL. Platelet counts and MPV were evaluated via Coulter LH analyzer. Elevated MPV was defined as a value $\geq 11 \mathrm{fl}$ based on Hussein's study (23), thrombocytopenia was defined as platelet $<150,000$ $\times 10^{9} / \mathrm{L}$, metabolic acidosis defined as $\mathrm{pH}<7.2$ and base deficit (BE) in the extracellular fluid $>12.0 \mathrm{mmol} / \mathrm{L}$.

\subsection{Statistical Analysis}

Enrolled infants were stratified into IVH and non-IVH groups. Clinical characteristics of infants were summarized as proportions for dichotomous variables and mean with standard deviation for continuous variables. Comparison of continuous and dichotomous variables between groups was done using Student's t-test and Chi square test, respectively. Since the sample size was small and data had several unbalanced and highly predictive risk factors (complete separation problem), multiple logistic regression model was performed using firthlogit to examine possible association between outcome of interest (IVH) and MPV. The presence of the aforementioned problem in logistic regression models can result in bias of odds ratio (OR) estimating away from 1 . Firthlogit command did not use maximum log likelihood but penalized log likelihood instead to reduce bias. All data analysis was completed using Stata version 14 (STATA Corp, College Station, TX).

\section{Results}

A total of 352 preterm and term infants were admitted to our hospital. Fifty premature infants with IVH were enrolled in the study. The control group consisted of 50 preterm infants who did not develop IVH.

Infants with IVH had lower birth weight (Mean difference: $0.48,95 \% \mathrm{CI}$ : 0.08 to $0.87, \mathrm{P}=0.018$ ) and $\mathrm{GA}$ (Mean difference: $2.9,95 \% \mathrm{CI}: 1.95$ to $3.92, \mathrm{P}<0.001$ ), compared to infants without IVH. The demographic characteristics, MPV and platelet counts for both groups are shown in Table 1. There was no statistically significant difference regarding other demographic characteristics.

Seventy four percent of infants with IVH had a MPV more than $11 \mathrm{fL}$ compared to twenty six percent in infants without IVH (Crude OR: 10.71, 95\%CI: 4.26 to 26.90 , P < 0.001). Correlation of MPV with IVH grades are shown in Table 2. Multivariate logistic regression analysis of selected variables demonstrated that MPV (Adjusted OR: 10.68, 95\%CI: 3.20 to $35.59, \mathrm{P}<0.001$ ) and GA (adjusted OR: $0.54,95 \% \mathrm{CI}: 0.40$ to $0.74, \mathrm{P}<0.001)$ were related to the occurrence of IVH. There was no significant association between IVH and other variables (Table 3). Platelet counts were similar in the first hours of life in both groups. On the third day of life, 70\% of infants in the IVH group had a platelet count less than 150000, in comparison with $20 \%$ in those without IVH $(\mathrm{P}=0.041)$.

In the IVH group, $100 \%$ of infants who had pneumothorax, had high MPV when compared to $67.5 \%$ of those who had no pneumothorax $(\mathrm{P}=0.036)$, and $100 \%$ of neonates with metabolic acidosis, had high MPV in comparison to $62.9 \%$ of those without metabolic acidosis $(\mathrm{P}=0.006)$.

\section{Discussion}

Despite the increasing survival rate of premature infants during recent decades, IVH is still one of the major causes of neurologic developmental problems (24-26). Inadequate functioning of autoregulation of cerebral blood 
Table 1. Characteristics of the Study Population ${ }^{a}$

\begin{tabular}{|c|c|c|c|}
\hline & $\begin{array}{c}\text { Infants with GMH-IVH (n } \\
=50)\end{array}$ & $\begin{array}{l}\text { Infants without GMH-IVH } \\
\qquad(\mathrm{n}=50)\end{array}$ & PValue \\
\hline GA, $w$ & $27.80 \pm 2.88$ & $30.74 \pm(1.97)$ & $<0.001$ \\
\hline Birth weight, $\mathrm{g}$ & & & 0.005 \\
\hline$<1000$ & $25(50)$ & $17(34)$ & \\
\hline $1001-1250$ & $20(40)$ & $15(30)$ & \\
\hline $1251-1500$ & 0 & $10(20)$ & \\
\hline $1501-1750$ & $5(10)$ & $8(16)$ & \\
\hline Maternal age & $32.50 \pm 7.67$ & $31.02 \pm(7.35)$ & 0.327 \\
\hline Parity & $1.40 \pm(1.03$ & $1.50 \pm(0.97)$ & 0.619 \\
\hline 1st minute Apgar score & $2.18 \pm 1.10$ & $2.12 \pm(1.08)$ & 0.417 \\
\hline 5th minute Apgar score & $5.69 \pm 2.43$ & $5.73 \pm 2.39$ & 0.432 \\
\hline Gender (male/female) & $35 / 15$ & $31 / 19$ & 0.527 \\
\hline $\begin{array}{l}\text { Mother's underlying } \\
\text { disease }\end{array}$ & & & 0.295 \\
\hline Yes & $15(30)$ & $20(40)$ & \\
\hline No & $35(70)$ & $30(60)$ & \\
\hline Modes of Delivery & & & 0.727 \\
\hline NVD & $4(8)$ & $5(10)$ & \\
\hline $\mathrm{c} / \mathrm{s}$ & $46(92)$ & $45(90)$ & \\
\hline Pneumothorax & & & 0.799 \\
\hline Yes & $10(20)$ & $9(18)$ & \\
\hline No & $40(80)$ & $41(78)$ & \\
\hline PDA & & & 0.171 \\
\hline Yes & $40(80)$ & $34(68)$ & \\
\hline No & $10(20)$ & $16(32)$ & \\
\hline Metabolic acidosis & & & 0.656 \\
\hline Yes & $15(30)$ & $13(26)$ & \\
\hline No & $35(70)$ & $37(74)$ & \\
\hline Sepsis & & & 1.000 \\
\hline Yes & $35(70)$ & $35(70)$ & \\
\hline No & $15(30)$ & $15(30)$ & \\
\hline MPV, fL & & & $<0.001$ \\
\hline$\geq 11$ & $37(74)$ & $10(20)$ & \\
\hline$<11$ & $13(26)$ & $40(80)$ & \\
\hline $\operatorname{PLT}\left(\times 10^{3} / \mathrm{mL}\right)$ & & & 0.041 \\
\hline$\geq 150,000$ & $15(30)$ & $25(50)$ & \\
\hline$<150,000$ & $35(70)$ & $25(50)$ & \\
\hline
\end{tabular}

flow has been considered as pathogenic factor in IVH (8). Furthermore, decreasing systolic and diastolic blood pressure as a result of increased serum levels of interleukins (ILs), especially IL-6, leads to IVH $(7,23)$. The effect of interleukins on platelet function in vascular inflammation have been noted by previous studies (27). During vascular inflammation and ischemic events interleukins as proinflammatory cytokines stimulate megakaryocytes to increase the number of platelets in response to inflammation that leads to high MPV (17).

In this study the feasibility of MPV within 24 hours of birth as an accessible tool to identify preterm infants prone to IVH in a large case group with lower gestational age was assessed.

In our study, preterm infants with IVH tend to have a high MPV in comparison with those without IVH, with significant difference. This was also studied by Cekmez et al. (28) and Bolouki Moghaddam et al. (20). Unlike their results we found this correlated with higher MPV. This difference may be due to lower GA (mean $27.80 \pm 2.88$ weeks) and lower birth weight (mean $1050 \pm 21.50$ grams) in our patients.

In Bolouki Moghaddam's study (20) mean MPV in the IVH group was $10.00 \pm 1.04$. In the study by Hussein et al19 mean MPV in the IVH group was $11.6 \pm 2.0$. Despite the fact that seventy four percent of our infants with IVH had a MPV of more than $11 \mathrm{fL}$, because high MPV was defined as $\geq 11 \mathrm{fL}$, we could not calculate mean MPV in the IVH group.

Canpolat et al reported high MPV in premature infants with RDS (18). We did not find any significantly increased MPV due to RDS. Even though the correlation between high MPV and inflammatory events especially sepsis (29) and BPD (20) have already been discussed, there are still a few studies with low sample size on assessing the role of high MPV to identify preterm infants prone to IVH and other morbidities during neonatal periods particularly in very premature infants. Multivariate logistic regression analysis of selected variables demonstrated that $\mathrm{MPV}(\mathrm{P}<0.001)$ and GA $(\mathrm{P}<0.001)$ were related to the occurrence of IVH. This may suggest that MPV and GA can be considered as independent risk factors for development of IVH as Hussein et al. did it (23). They considered MPV $>11 \mathrm{fL}$ as an independent risk factor that increased the risk of IVH $(\mathrm{P}<0.001)$. In their study male gender, birth weight $<1250 \mathrm{gr}$ and the 5th minute Apgar score $<8$ were considered as other independent risk factors of IVH (27). In our study there was no significant association between IVH and other variables. As our hospital has specialized units for high risk pregnancy and assisted reproductive systems (in vitro fertilization, egg freezing, etc), routine antenatal use of corticosteroids and in some cases magnesium sulfate along with administration of surfactants and using hybrid modes of mechanical ventilation after birth may explain the lack of other independent risk factors of IVH. $25 \%$ of neonates had IVH grade 1 , of whom $64.0 \%$ had MPV $>11.22 \%$ of neonates with MPV $>11$ had IVH grade 3,4. Although there are weak correlations between IVH grading and MPV $>11$ in comparison with the other group (Pvalue 0.055), unfortunately, the small number of IVH cases in each grade preclude a meaningful comparison between these IVH groups based on statistical analysis.

On the third day of life, thrombocytopenia was detected in the IVH group whereas it was not seen in the sec- 
Table 2. Assossiation of MPV with IVH Grades ${ }^{\mathrm{a}}$

\begin{tabular}{l|c|c|c|}
\hline IVH Grade & MPV $<\mathbf{1 1}$ & MPV $>\mathbf{1 1}$ & Total \\
\hline $\mathbf{1}$ & $9(36)$ & $16(64)$ & $25(100)$ \\
\hline $\mathbf{2}$ & 0 & $10(100)$ & $10(100)$ \\
\hline $\mathbf{3}$ & $4(40)$ & $6(60)$ & $10(100)$ \\
\hline $\mathbf{4}$ & 0 & $5(100)$ & $5(100)$ \\
\hline
\end{tabular}

${ }^{\mathrm{a}}$ Values are expressed as No. (\%).

Table 3. Adjusted Odds Ratio of GMH-IVH According to Selected Clinical and Demographic Characteristics by Multivariate Analysis

\begin{tabular}{|c|c|c|c|c|}
\hline Variables & Adjusted OR & Std. Err & 95\% CI & P Value \\
\hline MPV, fL & 10.68 & 6.54 & $3.20-35.59$ & $<0.001$ \\
\hline GA, w & 0.54 & 0.08 & $0.40-0.74$ & 0.006 \\
\hline Birth weight, $g$ & 1.49 & 0.50 & $0.76-2.90$ & 0.238 \\
\hline Maternal age & 0.99 & 0.03 & $0.93-1.07$ & 0.968 \\
\hline Parity & 0.94 & 0.59 & $0.45-1.92$ & 0.868 \\
\hline Mother's underlying disease & 1.43 & 1 & $0.36-5.70$ & 0.609 \\
\hline
\end{tabular}

ond group. This can be one of the relative risk factors for occurrence of IVH (30) and this is in concordance with MaydaDomac et al. (14) who found an inverse relationship between platelet count and MPV in preterm neonates. Larger size of younger platelets can explain this event.

In the IVH group, all of the infants with pneumothorax or metabolic acidosis had high MPV. Metabolic acidosis leads to arterial dilatation with hypotension and can damage the immune response (31). On the other hand, large fluctuation of CBF secondary to pneumothorax, ischemic and inflammatory events lead to IVH as a complication of pneumothorax. This may explain the higher MPV in these situations. According to our knowledge, this is the first time that the correlation of MPV and pneumothorax or metabolic acidosis has been studied. It seems that higher MPV index has the potential to act as a simple cost effective test for identifying critical preterm infants at the risk of IVH and can help early decision making of the care level and treatment that infants require.

\subsection{Limitation}

Despite proper sample size of our study in comparison to the previous studies, we were unable to achieve a meaningful comparison between high MPV with IVH grades due to the small numbers of IVH cases in each grade. Further studies are needed to evaluate the best cut-off value of MPV as a predicting factor in IVH. Multicenter studies in this regard will be more appropriate.

\subsection{Conclusions}

High MPV within 24 hours of birth could be determined as a simple available laboratory test for identifying the NICU-admitted premature infants at risk of IVH.

\section{Acknowledgments}

We would like to thank Mr. Sayyed Ourmazd Mohseni for editing the article.

\section{References}

1. Roberts D, Brown J, Medley N, Dalziel SR. Antenatal corticosteroids for accelerating fetal lung maturation for women at risk of preterm birth. Cochrane Database Syst Rev. 2017;3:CD004454. doi: 10.1002/14651858.CD004454.pub3. [PubMed: 28321847].

2. Pinto Cardoso G, Abily-Donval L, Chadie A, Guerrot AM, Pinquier $D$, Marret S, et al. [Epidemiological study of very preterm infants at Rouen University Hospital: changes in mortality, morbidity, and care over 11 years]. Arch Pediatr. 2013;20(2):156-63. doi: 10.1016/j.arcped.2012.11.011. [PubMed: 23266166].

3. Bajwa NM, Berner M, Worley S, Pfister RE, Swiss Neonatal N. Population based age stratified morbidities of premature infants in Switzerland. Swiss Med Wkly. 2011;141:w13212. doi: 10.4414/smw.2011.13212. [PubMed: 21706450].

4. Adams-Chapman I, Hansen NI, Stoll BJ, Higgins R, Nichd Research Network. Neurodevelopmental outcome of extremely low birth weight infants with posthemorrhagic hydrocephalus requiring shunt insertion. Pediatrics. 2008;121(5):e1167-77. doi: 10.1542/peds.2007-0423. [PubMed: 18390958].

5. Horbar JD, Carpenter JH, Badger GJ, Kenny MJ, Soll RF, Morrow KA, et al. Mortality and neonatal morbidity among infants 501 to 1500 grams from 2000 to 2009. Pediatrics. 2012;129(6):1019-26. doi: 10.1542/peds.2011-3028. [PubMed: 22614775]. 
6. Mitsiakos G, Papathanasiou AE, Kyriakidis I, Karagianni P, Tsepis K, Tzimou I, et al. Intraventricular Hemorrhage and Platelet Indices in Extremely Premature Neonates. J Pediatr Hematol Oncol. 2016;38(7):5338. doi: 10.1097/MPH.0000000000000631. [PubMed: 27849673].

7. Lou HC, Lassen NA, Friis-Hansen B. Impaired autoregulation of cerebral blood flow in the distressed newborn infant. J Pediatr. 1979;94(1):118-21. [PubMed: 758388].

8. Heep A, Behrendt D, Nitsch P, Fimmers R, Bartmann P, Dembinski J. Increased serum levels of interleukin 6 are associated with severe intraventricular haemorrhage in extremely premature infants. Arch Dis Child Fetal Neonatal Ed. 2003;88(6):F501-4. [PubMed:14602698].

9. Furukawa S, Sameshima H, Ikenoue T. Circulatory disturbances during the first postnatal 24 hours in extremely premature infants 25 weeks or less of gestation with histological fetal inflammation. J Obstet Gynaecol Res. 2008;34(1):27-33. doi: 10.1111/j.14470756.2007.00678.x. [PubMed: 18226125].

10. Basu S, Agarwal P, Anupurba S, Shukla R, Kumar A. Elevated plasma and cerebrospinal fluid interleukin-1 beta and tumor necrosis factoralpha concentration and combined outcome of death or abnormal neuroimaging in preterm neonates with early-onset clinical sepsis. J Perinatol. 2015;35(10):855-61. doi: 10.1038/jp.2015.86. [PubMed: 26226245].

11. Szpecht D, Wiak K, BraszakA, Szymankiewicz M, Gadzinowski J. Role of selected cytokines in the etiopathogenesis of intraventricular hemorrhage in preterm newborns. Childs Nerv Syst. 2016;32(11):2097-103. doi: 10.1007/s00381-016-3217-9. [PubMed: 27541865].

12. Chu SG, Becker RC, Berger PB, Bhatt DL, Eikelboom JW, Konkle B, et al. Mean platelet volume as a predictor of cardiovascular risk: a systematic review and meta-analysis. J Thromb Haemost. 2010;8(1):148-56. doi: 10.1111/j.1538-7836.2009.03584.x. [PubMed: 19691485].

13. Martin JF, Plumb J, Kilbey RS, Kishk YT. Changes in volume and density of platelets in myocardial infarction. Br Med J (Clin Res Ed). 1983;287(6390):456-9. [PubMed: 6411172].

14. Mayda-Domac F, Misirli H, Yilmaz M. Prognostic role of mean platelet volume and platelet count in ischemic and hemorrhagic stroke. J Stroke Cerebrovasc Dis. 2010;19(1):66-72. doi: 10.1016/j.jstrokecerebrovasdis.2009.03.003. [PubMed: 20123229].

15. Bath PM, Butterworth RJ. Platelet size: measurement, physiology and vascular disease. Blood Coagul Fibrinolysis. 1996;7(2):157-61. [PubMed: 8735807].

16. Santimone I, Di Castelnuovo A, De Curtis A, Spinelli M, Cugino D, Gianfagna F, et al. White blood cell count, sex and age are major determinants of heterogeneity of platelet indices in an adult general population: results from the MOLI-SANI project. Haematologica. 2011;96(8):1180-8. doi: 10.3324/haematol.2011.043042. [PubMed: 21546503].

17. Yazici S, Yazici M, Erer B, Erer B, Calik Y, Ozhan H, et al. The platelet indices in patients with rheumatoid arthritis: mean platelet volume reflects disease activity. Platelets. 2010;21(2):122-5. doi: 10.3109/09537100903474373. [PubMed: 20050760].

18. Canpolat FE, Yurdakok M, Armangil D, Yigit S. Mean platelet volume in neonatal respiratory distress syndrome. Pediatr Int. 2009;51(2):314-6. doi: 10.1111/j.1442-200X.2009.02820.x. [PubMed: 19379270].

19. Nourripoor S, Tabasizadeh H, Afjehi A, Ghorbani R, Seifhashemi M, Masoudian N. Could mean platelet volume predict developing of bronchopulmonary dysplasia in preterm infants with respiratory distress syndrome?. Iran J Neonatol IJN. 2013;4(3):35-41.

20. Bolouki Moghaddam K, Zarkesh M, Kamali A, Dalili S, Heidarzadeh A, Hassanzadeh Rad A. The Association of Mean Platelet Volume with Intra Ventricular Hemorrhage and Broncho Pulmonary Dysplasia in Preterm Infants. Iran J Ped Hematol Oncol. 2015;5(4):227-32. [PubMed: 26985356].

21. Sweet DG, Carnielli V, Greisen G, Hallman M, Ozek E, Plavka R, et al. European consensus guidelines on the management of neonatal respiratory distress syndrome in preterm infants-2013 update. Neonatology. 2013;103(4):353-68. doi: 10.1159/000349928. [PubMed: 23736015].

22. Volpe J. In: Neurology of the Newborn. Volpe J, editor. Philadelphia: Saunders; 2008. pp. 517-88.Intracranial Hemorrhage Germinal Matrix-Intraventricular hemorrhage of the premature Infants.

23. Hussein NF, Helaly NSE, Ghanya EAA, Anisb SK. Relationship between mean platelet volume and bronchopulmonary dysplasia and intraventricular hemorrhage in very low birth weight neonates. J Am Sci. 2012;8(5).

24. Vela-Huerta MM, Amador-Licona M, Medina-Ovando N, AldanaValenzuela C. Factors associated with early severe intraventricular haemorrhage in very low birth weight infants. Neuropediatrics. 2009;40(5):224-7. doi: 10.1055/s-0030-1248249. [PubMed: 20221958].

25. Ancel PY, Livinec F, Larroque B, Marret S, Arnaud C, Pierrat V, et al. Cerebral palsy among very preterm children in relation to gestational age and neonatal ultrasound abnormalities: the EPIPAGE cohort study. Pediatrics. 2006;117(3):828-35. doi: 10.1542/peds.2005-0091. [PubMed: 16510664].

26. Patra K, Wilson-Costello D, Taylor HG, Mercuri-Minich N, Hack M. Grades I-II intraventricular hemorrhage in extremely low birth weight infants: effects on neurodevelopment. J Pediatr. 2006;149(2):169-73. doi: 10.1016/j.jpeds.2006.04.002. [PubMed: 16887428].

27. von Vietinghoff S, Ley K. Interleukin 17 in vascular inflammation. Cytokine Growth Factor Rev. 2010;21(6):463-9. doi: 10.1016/j.cytogfr.2010.10.003. [PubMed: 21075042].

28. Cekmez F, Tanju IA, Canpolat FE, Aydinoz S, Aydemir G, Karademir $\mathrm{F}$, et al. Mean platelet volume in very preterm infants: a predictor of morbidities?. Eur Rev Med Pharmacol Sci. 2013;17(1):134-7. [PubMed: 23329535].

29. Aydin B, Dilli D, Zenciroglu A, Karadag N, Beken S, Okumus N. Mean platelet volume and uric acid levels in neonatal sepsis. Indian JPediatr. 2014;81(12):1342-6. doi: 10.1007/s12098-014-1417-4. [PubMed: 24733619].

30. von Lindern JS, van den Bruele T, Lopriore E, Walther FJ. Thrombocytopenia in neonates and the risk of intraventricular hemorrhage: a retrospective cohort study. BMC Pediatr. 2011;11:16. doi: 10.1186/14712431-11-16. [PubMed: 21314921].

31. Kraut JA, Madias NE. Metabolic acidosis: pathophysiology, diagnosis and management. Nat Rev Nephrol. 2010;6(5):274-85. doi: 10.1038/nrneph.2010.33. [PubMed: 20308999]. 